\title{
Agronomic Performance and Flowering Behavior in Response to Photoperiod and Vernalization in Barley (Hordeum vulgare L.) Genotypes with Contrasting Drought Tolerance Behavior
}

\section{Jamal Abu-Elenein}

The University of Jordan

\section{Rabea Al-Sayaydeh}

Al-Balqa Applied University

\section{Zahera Akkeh}

The University of Jordan

\section{Zakaria Al-Ajlouni}

Jordan University of Science and Technology

AbdRaheem A. Al-Bawalize

NARC

\section{Shireen Hasan}

The University of Jordan

\section{Tariq Hindi}

The University of Jordan

\section{Randa Rahahla}

The University of Jordan

\section{Jamal Y. Ayad}

The University of Jordan

Ayed M. Al-Abdallat ( $\square$ a.alabdallat@ju.edu.jo )

The University of Jordan

\section{Research Article}

Keywords: Barley, Drought, Flowering time, Gene Expression, Photoperiod, Vernalization

Posted Date: March 15th, 2021

DOl: https://doi.org/10.21203/rs.3.rs-289948/v1

License: (c) (i) This work is licensed under a Creative Commons Attribution 4.0 International License. 


\section{Abstract}

\section{Background}

In barley, flowering behavior is a highly regulated and complex process where the appropriate matching of reproductive development with seasonal variation in water availability confer barley adaptation to different environments. In this study, the role of variation in flowering time and drought tolerance in four selected barley genotypes was studied under field and controlled conditions. For this purpose, field trials were conducted for two consecutive seasons at three diverse environments where the studied genotypes were subjected to either rainfed conditions or rainfed plus supplementary irrigation under two different sowing dates. Furthermore, reproductive meristem development in two selected barley genotypes, Rum (drought tolerant) and Steptoe (drought-sensitive) was also assessed in response to both vernalization and water stress under two different photoperiod conditions.

\section{Results}

Variation in the number of days to heading was more pronounced under rainfed conditions than under well water conditions. For agronomic performance, Rum was superior under all tested environments, which assure its general adaptability to multiple environments, while Steptoe was the poorest. The transition to reproductive meristem was faster under vernalized long-day conditions as compared to vernalized short-day conditions. The progress of shoot apical meristem development and heading under long-day conditions was significantly faster in Rum than that of Steptoe. A clear effect of drought stress was observed on shoot apical meristem development in Steptoe. Under short-day conditions, vernalized Rum plants subjected to water deficit showed an advanced meristem development stage a significant earlier HD when compared with non-stressed plants. This early flowering behavior in stressed Rum plants under short-day conditions was accompanied by higher gene expression of the $\mathrm{Vrn}-\mathrm{H} 1 \mathrm{gene}$.

\section{Conclusion}

In conclusion, the integration of vernalization and photoperiod signals in drought-tolerant barley genotypes is associated with early flowering behavior and higher productivity in dry environments.

\section{Background}

Barley is considered one of the most important cereal crops in the world in terms of harvested area, trade value and human nutrition [1]. It is commonly used for human consumption, animal feed and malting and it is considered the crop of choice in marginal and dry areas [2]. In eastern parts of the Mediterranean basin, barley is generally grown in arid and semi-arid areas that are characterized by low amounts of precipitation and prolonged drought conditions [3]. As a rainfed crop, barley is frequently suffering from drought that occurs when the soil water content is not available in sufficient amounts to support normal growth and development [4]. To maintain a sustainable increase in barley yield, the development of hratinn_cnonifin and hinh-vialdinn variatioc with imnravad tolerance to abiotic stresses is needed [3]. Loading [MathJax]/jax/output/CommonHTML/fonts/TeX/fontdata.js 
Drought stress has always played an important selective role in the evolution of plant growth, development and physiology [5]. Plant adaptation to dry conditions is considered a key factor that will determine the future of crop production systems in response to climate change and associated conditions [6]. In this perspective, shifting planting dates or switching to short growing-season varieties are considered a useful strategy to reduce the negative impact of climatic change and associated stresses such as drought and heat stress [7]. Therefore, flowering time is an important trait for crop adaptation to particular environments and their associated abiotic stresses [8]. The ability to regulate flowering time in cereal plants will enable them to complete their life cycle successfully under a wide range of environments [9].

Flowering is a crucial event in the life cycle of seed propagated plants and is usually affected by different environmental stimuli [8]. Timing of flowering, also known as heading date in cereals, is a major trait that is linked to the adaptation to particular environments and it determines the crop performance under field conditions $[10,11]$. In temperate cereals, photoperiod sensitivity and vernalization requirements are major cues that determine flowering behavior [9]. Vernalization accelerates flowering by promoting inflorescence initiation, the first step in the transition of the shoot apex to the reproductive phase [12]. Furthermore, vernalization is an adaptation process that prevents the exposure of sensitive floral meristems to freezing winter temperatures [9]. Winter barley requires vernalization and therefore, they are planted in the fall and require long exposures to cold temperatures during winter to accelerate flowering [13]. On the other hand, spring barley is usually planted in spring and does not require vernalization to flower [10]. On the other hand, photoperiod is a major factor determining cereal plant flowering and crop performance in response to day length [8]. In barley, a long-day (LD) plant, flowering occurs when the day becomes longer than a critical day length [14]. Photoperiod insensitive barley enables the initiation of floral primordia without requirements for LD photoperiod, whereas sensitive genotypes need LD conditions for floral primordia initiation [15].

The manipulation of flowering time in barley may strongly affect its adaptation to marginal areas and associated stresses [16]. Early genetic analysis indicates the presence of a correlation between growth habit and stress tolerance where spring barley genotypes were less freezing tolerant when compared with winter types [17]. Allelic differences and their combinations in vernalization- (VRM) and photoperiodrelated $(P P D)$ genes seem to have a large effect on stress tolerance in temperate cereals $[18,19]$. For instance, the PHOTOPERIOD-H1 (Ppd-H1) gene was found to control stress-induced senescence in barley roots subjected to osmotic stress [20] and most recently it was found to control the plasticity of development in response to drought [21]. In another study, barley genotypes carrying spring VERNALIZATION-H1 (Vrn-H1) alleles showed an accelerated flowering under drought stress when compared with genotypes carrying winter alleles [22]. Therefore, the interaction between environmental cues, such as day-length and low-temperatures, and the allelic variations in major flowering time genes, such as Ppd-H1 and $\mathrm{Vrn}-\mathrm{H} 1$, might affect the flowering behavior and adaptation of barley to dry conditions [10]. 
The matching of reproductive development and the time of flowering to the temporal variation in water availability is recognized as one of the most important traits for plant adaptation to drought $[8,10]$. In this study, we analyzed the flowering behavior, reproductive meristem development, growth and physiological responses to drought conditions in two selected spring barley genotypes with contrasting drought tolerance behavior. For this purpose, the flowering behavior and agronomic performance of droughttolerant and drought-sensitive barley genotypes were studied at different contrasting envirnoments and management practices for two growing seasons. Thereafter, the impact of drought stress on two selected barley genotypes with contrasting drought tolerance behavior genotypes was assessed under controlled conditions with different vernalization and photoperiod treatments. The expression patterns of $P p d-H 1$ and $\mathrm{Vrn}-\mathrm{H} 1$ genes were investigated in both selected genotypes in response to drought, vernalization and photoperiod treatments. The presented results showed that drought effects varied in response to vernalization and photoperiod treatments in the tested genotypes, highlighting the importance of phenological adjustment in barley for better adaption to dry environments.

\section{Methods}

\section{Plant material}

Four barley genotypes with contrasting drought tolerance behavior were used in this study [22]: Rum cultivar (Harbinger-Arivat $\times$ Attiki; released in Jordan in 1986) was developed by CIMMYT/ICARDA and it is known for its stable productivity under arid conditions and is considered a drought-tolerant genotype. Acsad176 (CM872-189-3Y-1B-2Y-1BX1Y-OB) $\times(C r .366 / 16 / 2))$ developed by ACSAD center and commonly grown in semi-arid regions in Jordan where supplementary irrigation is recommended. Steptoe (Washington Selection 3564/Unitan) is derived from coast-type barley originating in North Africa and is considered a drought-sensitive genotype [22]. Morex is a spring smooth-awned spring barley cultivar derived from Manchurian barley (Cree/Bonanza). All selected genotypes are spring types (carrying dominant spring $\mathrm{Vrn}-\mathrm{H} 1$ alleles) and all carry a functional $\mathrm{Ppd}-\mathrm{H} 1$ allele conferring photoperiodic responses to LD conditions except for Morex, which carries a nonfunctional ppd-H1 allele. All four genotypes were used for field trials, while Rum and Steptoe were selected for the controlled conditions experiment.

\section{Field trials}

The field trials were conducted in three agricultural stations across Jordan for two growing seasons (2011-2012 and 2012-2013). The first station was at the University of Jordan (JU) campus (Jubeiha Agricultural Research Station; 32 $00^{\prime} 40^{\prime \prime}$ N, 3552'24" E; elevation: 990 m; average annual precipitation: $505 \mathrm{~mm}$; soil type: clay loam) representing a semi-humid area. The second station was at the Jordan University of Science and Technology (JUST) campus research station (Ramtha; $32^{\circ} 28^{\prime} 47.4^{\prime \prime} \mathrm{N}$, 3559'11.1" E; elevation: $520 \mathrm{~m}$; average annual precipitation: $217 \mathrm{~mm}$; soil type: clay loam) representing 
$31^{\circ} 16^{\prime} 37.1^{\prime \prime} \mathrm{N}, 35^{\circ} 44^{\prime} 26.9^{\prime \prime}$ E; elevation: $920 \mathrm{~m}$; average annual precipitation: $337 \mathrm{~mm}$; soil type: clay) representing a semi-dry area. In each trial, the four tested genotypes were sown at two different dates: 1st of December and 1st of February. Furthermore, the genotypes were cultivated in each field trial under either rainfed or supplementary-irrigation conditions. The weather data and the amount of supplementary irrigation applied are provided in Additional file 1.

A split-split plot design with four replications was used where each replicate contained two plots for irrigation and rainfed treatments and each plot contains two subplots for planting date treatments. Each subplot area contained the four tested genotypes randomly distributed within the plot with each genotype sown in two adjacent rows ( $1.5 \mathrm{~m}$ length and $0.3 \mathrm{~m}$ apart). The seeding rates were adjusted according to the results of a seed germination test (based on $90 \%$ germination) to obtain a plant density from the viable seeds of 50 plants/row (approximately 150 plants $/ \mathrm{m}^{2}$ ). In irrigated plots, average soil moisture in the first $60 \mathrm{~cm}$ depth was maintained at $80 \%$ of field capacity, which was estimated each week after sowing using soil HH2 moisture meter with Profile Probe type PR2 (DELTA-T Devices, Cambridge, England). All field experiments followed a fallow in the crop rotation and were established using hand broadcasting following conventional tillage performed with a chisel plow and disk harrow. In each location, experimental plots were managed following the standard agricultural practices including fertilizer application to match the crop needs, weed control (hand weeding and herbicides against broadleaf weeds) and pesticide use against main pathogens. Weather stations at the field sites were used to record precipitation and temperature during the growing seasons.

\section{Field trials data analysis}

During plant growth and before harvest, the following data were collected: days to heading (HD: days) that was determined visually by calculating the number of days from emergence to the day when $50 \%$ of plants had spikes; days to physiological maturity (MD: days) that was determined visually by calculating the number of days from emergence to the day when $90 \%$ of the plants in a plot have reached the physiological maturity stage (no green tissue remained in $90 \%$ of the plants in each plot); Grains filling period (GFP: days) that was estimated by substracting MD from HD; plant height (PH: $\mathrm{cm}$ ) that was measured for each genotype at maturity from the ground to the spike tip (excluding awns) on three selected plants randomly distributed in the rows; peduncle length $(\mathrm{PL}: \mathrm{cm})$ that was measured as the distance from the flag leaf collar to the base of the spike on the same main stem of the plants used to measure plant height and whenever the value is negative, this indicates that the spike remained inside the sheet of the flag leaf. At the end of the experiment, plants for each treatment were harvested and the following measurements were recorded: total plant weight $\left(\mathrm{TW}: \mathrm{g} / \mathrm{m}^{2}\right)$ that was measured as the whole dry weight of the harvested plants; spikes number (SN) as the number of spikes counted per $\mathrm{m} 2$; spikes weight (SPW: $\mathrm{g} / \mathrm{m}^{2}$ ) that was measured by weighing the spikes obtained from harvested plants; Straw weight (STW: $\mathrm{g} / \mathrm{m}^{2}$ ) that was obtained by subtracting spikes weight from the total plant weight; for grains weight $\left(G W: g / m^{2}\right)$, spikes were separated and threshed and the grains were cleaned from the Loading [MathJax]/jax/output/CommonHTML/fonts/TeX/fontdata.js by dividing grains number on the total spikes 
number; grains number (GN: grains $/ \mathrm{m}^{2}$ ) was obtained by counting the harvested seeds using a seed counter; thousand kernel weight (TKW: g) was calculated by dividing the number of the grains by grains weight multiplied by 1000; harvest index (HI: \%) was calculated by dividing grain weight over total plant weight multiplied by 100 .

For statistical analysis, the multi-environment field trials data were analyzed as a split-split plot design using the GenStat statistical software (Release 16.1, 2013; VSN International L) and a combined analysis of variance (ANOVA) was obtained. For this purpose, each location-growing season combination was considered an environment resulting in six environments: JU2012, JU2013, JUST2012, JUST2013, RB2012 and RB2013. The ANOVA was conducted to analyze the variations due to environments, sowing dates, water regimes, genotypes and all of their interactions. The coefficients of variation (CV\%) was determined for each trait and when significant differences were detected, a comparison of means was conducted using the least significant difference test (LSD, $P<0.05)$ to determine the performances of tested genotypes under all treatment combinations. Pearson correlation coefficients were calculated in the R software 4.0.2 using the metan package [23] using the means for all or selected combinations of environments, genotypes, water regimes and sowing dates. To analyze the specific adaptation, superiority, and stability of the genotypes across tested environments for the GW trait, the GGE function [24] of the metan package [23] was used. For this purpose, each environment-sowing date-water regime combinations were considered as one distinctive group.

\section{Controlled conditions experiment}

To test the effect of water deficit, vernalization and photoperiod on flowering behavior and physiological responses in Rum (drought tolerant) and Steptoe (drought-sensitive), a pot experiment was conducted under controlled growth conditions. For the vernalization treatment, seeds of both genotypes were imbibed with distilled water and planted ( 2 seeds per pot) in foil-covered pots $(30 \mathrm{~cm}$ length and $20 \mathrm{~cm}$ diameter) containing a mixture of sand and perlite (2:1) and were subjected to 45 days of vernalization at $4{ }^{\circ} \mathrm{C}$ under complete darkness as described previously [25]. After vernalization, the seedlings were transferred to growth chamber conditions, either under LD (16 h light/8 h dark) or short-day (SD: $8 \mathrm{~h}$ light/16 $\mathrm{h}$ dark) conditions depending on the photoperiod treatment, along with non-vernalized 7-days old seedlings (germinated under complete darkness). After one week, leaf number was counted in vernalized and non-vernalized seedling and those plants with leaf number similar to that of 7 days-old seedlings were selected for further analysis [25]. Both vernalized and non-vernalized selected seedlings were grown under either SD or LD conditions at $22 \pm 1^{\circ} \mathrm{C}$ with a light intensity level of $56 \mu \mathrm{mol} \mathrm{m}^{-2} \mathrm{~s}^{-1}$ and the plants were allowed to grow up to 120 days.

For drought treatments, the seeds of both vernalized and non-vernalized plants were exposed to wellwatered and water deficit conditions under two different photoperiods (LD and SD) as described above. The treated seedlings (vernalization and photoperiod) of both tested genotypes were subjected to water

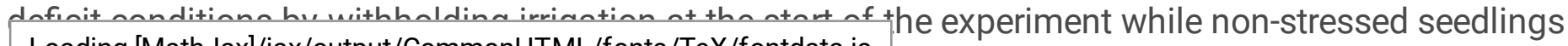
Loading [MathJax]/jax/output/CommonHTML/fonts/TeX/fontdata.js 
were kept hydrated and were used as control. Water levels were maintained at $75 \%$ of pot capacity for non-stressed plants and $15 \%$ of pot capacity for stressed plants [26]. The soil moisture levels for the pots of the well-watered and drought-stressed conditions were maintained at the targeted pot capacity by irrigating the required amounts of water after measuring soil water content using a Delta-T soil moisture probe device (Theta Probe type ML2X, Delta-T Devices, Cambridge, England).

\section{Physiological and growth measurements of controlled conditions experiment}

Leaf relative water content (RWC) was measured biweekly for the first eight weeks of the experiment as described previously [27] and the RWC was calculated according to [28]. Stomatal resistance was also measured on the most upper fully expanded leaf biweekly for the first eight weeks of the experiment by using a Porometer device (AP4, Delta-T Devices, Cambridge, UK). For leaf chlorophyll fluorescence yield, measurements were recorded directly by using a Pulse-Modulated Fluorometer (OS1-FL modulated chlorophyll fluorometer, ADC Bio Scientific Ltd., Hertford, UK). Fluorescence measurements were taken after 20 min of acclimation to darkness under leaf clips (FL-DC; Opti-Sciences). The maximum quantum efficiency $(F v / F m)$ of photosystem II was calculated as $F v / F m=(F m-F O) / F m$, where $F m$ and $F O$ are the maximal and minimal chlorophyll fluorescence measured in darkness-adapted leaves, respectively.

For meristem development, plants were sampled biweekly for the first eight weeks of the experiment. Shoot apices were dissected under a binocular dissecting microscope (LAS EZ, Leica Microsystems, Switzerland) and digitally photographed by using a digital camera. Phenotypic meristem development was scored according to the Waddington scale [29] using four plants per experimental treatment. The HD was recorded based on the number of days between emergence and heading following Zadoks scale [30]. A comparison between means was conducted using the standard error of means to determine the performances of the two genotypes under all treatment combinations.

\section{Gene expression analysis}

For quantitative real-time PCR (qRT-PCR) analysis of treated barley plants (controlled conditions experiment), total RNA was isolated from leaf samples collected after 10 hours from the onset of light conditions irrespective of the photoperiod or vernalization conditions. The leaf samples were collected after two and four weeks for LD treated plants and after four and six weeks for SD treated plants. Specific primers pairs for two major flowering genes in barley (Vrn-H1: fwd: 5

- $T G \forall$ GCTCAG $\forall A T G G A$ T CG - 3 and Rev: 5- TATGAGCGCTACTC T ATGC - 3; [31]) and (PpdH1: fwd: 5- $C \forall A T C \forall A G A G C G G C G A T G$ - 3 and Rev: 5- TCTGAC T GGGATGG T CACA - 3; [32]) were used. For stress-inducible gene expression, specific primers pair for the HVA22 gene [33] were used (fwd: 5- ATGGGC $\forall A T C A T G G G C G C T$ - 3 and Rev: 5- TGCAC T GTGATCGGCGTC - 3) and HvActin (encodina actin. a house-keepina aene that was used as an internal reference control for relative Loading [MathJax]/jax/output/CommonHTML/fonts/TeX/fontdata.js 
gene expression analysis as described in [27]. The amplification of the targeted genes was carried out using the GoTaq ${ }^{\circledR}$ qPCR Master Mix Kit following the manufacturers' instructions (Promega, Madison, WI, USA), and the real-time detection of the amplified products was performed in a Mini-Opticon Real-Time PCR System (BioRad, Hercules, CA, USA). All cDNA samples were analyzed in triplicate, and each replicate was derived from two biological replicates. Thermal cycling conditions consisted of an initial denaturation step of $94^{\circ} \mathrm{C}$ for 5 minutes followed by 40 cycles of $94^{\circ} \mathrm{C}$ for $30 \mathrm{~s}, 55^{\circ} \mathrm{C}$ for $30 \mathrm{~s}$ and $72^{\circ} \mathrm{C}$ for $45 \mathrm{~s}$, followed with a final extension at $72^{\circ} \mathrm{C}$ for $5 \mathrm{~min}$. The relative changes in gene expression were quantified as described in [34].

\section{Results}

\section{Field trials}

Analyzing weather data during the two growing seasons (2012 and 2013) in the three locations indicates that January and February were the coldest months (Additional file 1). During this time, all field trials were exposed to temperatures less than $5{ }^{\circ} \mathrm{C}$ indicating that the tested genotypes were exposed to vernalization conditions. For rainfall amounts, RB station received $\sim 10 \%(33.5 \mathrm{~mm})$ less precipitation than the long-term average of rainfall during the first growing season, while JU and JUST stations received $11.5 \%(58 \mathrm{~mm})$ and $40 \%(86.5 \mathrm{~mm})$ more than the long term average of rainfall, respectively (Additional file 1). During the second growing season, all locations received more rainfall than the longterm average where RB received 3\% (11 mm), JU 6\% (28 mm) and JUST 10\% (20.6 mm) above long-term average of rainfall. The rainy season in 2012 was terminated in April in all stations and was accompanied by high temperatures at the end of the season (Additional file 1). In 2013, the rainy season was terminated earlier than expected in Rabbah starting March, while only $7.8 \mathrm{~mm}$ were received in JUST that resulted in severe terminal drought conditions. The amounts of water provided by supplementary irrigation for irrigated plots are given in Additional file 1.

The combined ANOVA for the studied traits showed highly significant differences $(P<0.01)$ between genotypes, locations, water regimes, sowing dates, and their interactions (Additional file 2). The mean values for the studied traits across the six environments and their combinations with the sowing date and water regime are given in Additional file 3. For correlation analysis, positive significant correlations $(P<$ 0.01) were found between all traits where GY showed a strong correlation with yield component-related traits and to less extent with HD, MD and GFP traits (Additional file 4).

The mean values of GY of tested genotypes (main effect of genotype) ranged from $585 \mathrm{~g} / \mathrm{m}^{2}$ in Rum (significantly the highest genotype) to the significantly lowest mean value of $367 \mathrm{~g} / \mathrm{m}^{2}$ in Steptoe. The main effect of sowing date treatment showed that December produced significantly the highest GY mean value $\left(605 \mathrm{~g} / \mathrm{m}^{2}\right)$ compared with February $\left(341 \mathrm{~g} / \mathrm{m}^{2}\right)$. The main effect of water regime treatment showed a significantly higher GY mean value for irrigated treatment $\left(650 \mathrm{~g} / \mathrm{m}^{2}\right)$ when compared with rainfed $\left(296 \mathrm{~g} / \mathrm{m}^{2}\right)$. The combined effect of the sowing date, water regime and genotype on GY showed 
high significancy level $(P<0.01)$ (Additional file 2). Rum produced significantly the highest mean value of $\mathrm{GY}\left(889 \mathrm{~g} / \mathrm{m}^{2}\right)$ under irrigated conditions and December sowing date, while Steptoe produced significantly the lowest mean value of $G Y\left(73 \mathrm{~g} / \mathrm{m}^{2}\right)$ under rainfed conditions and February sowing date where Rum produced $188 \mathrm{~g} / \mathrm{m}^{2}\left(\operatorname{LSD}_{(0.05)}=13.9\right)$. The interaction between environments, water regime, sowing date and genotypes showed a clear significant effect on the GY (Additional file 2; Additional file 3; Fig. 1a). For instance, Steptoe produced significantly the lowest mean value $\left(50 \mathrm{~g} / \mathrm{m}^{2}\right)$ for $\mathrm{GY}$ under rainfed conditions in JUST-2013 for December sowing date treatment, while Rum produced $388 \mathrm{~g} / \mathrm{m}^{2}$ (Additional file 3). In JUST-2013, no significant differences were found between GY mean values of all tested genotypes under rainfed treatment for February sowing date, however, Steptoe produced significantly the lowest GY mean values in all remaining environments (Additional file 3). Under irrigated conditions, Rum and Acsad176 produced significantly the highest mean values for GY across all environments irrespective of sowing date treatment except for Steptoe sown in December in JU2012 where no significant differences were observed with Rum and Acsad176 GY mean values (Additional file $3)$.

For HD, the mean values of tested genotypes ranged from 90.2 days in Rum (significantly the fastest genotype to flower) to the significantly lowest mean value (107.6 days) recorded in Steptoe. For the main effect of the sowing date, December produced significantly the highest HD mean value (116.7 days) when compared with February (75.7 days). For the main effect of the water regime, the irrigation treatment produced significantly the highest HD mean value (97.8 days) when compared with rainfed (94.7 days). The effect of interaction between sowing date and water regime treatments on HD indicates the presence of significant differences between tested genotypes (Additional file 2). The interaction between environments, water regime, sowing date and genotype showed a clear significant effect on HD (Additional file 2; Additional file 3; Fig. 1b). For instance, Steptoe produced the highest mean values for $\mathrm{HD}$ in any given environment $\times$ water regime combinations for December sowing date treatment (Fig. 1b; Additional file 3). For February sowing date treatment, clear significant differences were identified only in 2013 environments (JU-2013, RB-2013 and JUST-2013) between HD mean values of Steptoe and other genotypes irrespective of water regime treatments (Additional file 3).

To analyze genotype-specific adaptation to specific environment for the GY trait, the GGE biplot was used. For this purpose, the environments were reclassified based on the combination of each location, year, sowing date and water regime treatments to produce 24 distinct environments. The relationships between the GY of tested genotypes and the 24 tested environments and the degree by which each environment is represented are shown in Fig. 2a. The two principal components (PC1 and PC2) together captured $98.32 \%$ of the interaction effects and the variations due to GGE. Three irrigated environments from the 2013 season fell in the sector in which Acsad176 cultivar was the vertex genotype, which means that Acsad176 was the best genotype in these environments (Fig. 2a). On the other hand, Rum was the winner cultivar in the rest of the environments (21 out of 24) and specifically in all rainfed environments irrespective of location, sowing date or season. By contrast, Morex and Steptoe did not win in any testing 
all tested environments (Fig. 2a). Interestingly, both genotypes were placed on different sectors indicating different responses to tested environments. For stability as measured by projection to the Average-Tester Axis y-axis, Rum was the most stable followed by Acsad176, while Steptoe and Morex were considered the least stable genotypes (Fig. 2b).

Based on the results above and to analyze the relationship between heading date and agronomic performance, a new correlation analysis was perfumed using the field data of Rum and Steptoe after reclassifying the environments into four different groups based on the combination of sowing dates and water regime treatments (December-irrigated, December-rainfed, February-irrigated and February-rainfed). As shown in Additional file 5, negative significant correlations $(P<0.05)$ were found across the four groups between HD with GW and SPW. For December-irrigated conditions (Additional file 5), the negative significant correlations with $\mathrm{HD}$ included $\mathrm{HI}$ and TKW, while for December-rainfed conditions the negative significant correlations with HD included TW and STW (Additional file 5). For the February sowing date and irrespective of water regime treatment, negative significant correlations were detected between $\mathrm{HD}$ with TW, SN, GN, G.S. TKW and HI (Additional file 5).

\section{Controlled conditions experiment}

In this study, the transition to reproductive stage under LD was significantly faster in Rum genotype when compared with Steptoe irrespective of photoperiod, vernalization and water regime combinations (Fig. 3; Additional file 6). Under LD conditions, Steptoe reproductive meristem was in an advanced developmental stage under well-watered conditions when compared with stressed plants irrespective of vernalization treatment (Fig. 3a; Additional file 6). After eight weeks of LD incubation under well-watered conditions, non-vernalized Steptoe reproductive meristem was in an advanced developmental stage when compared with well-watered and vernalized Steptoe plants. For Rum plants grown under LD conditions, a significant difference was observed only after four weeks of incubation between well-watered and non-vernalzied plants when compared with well-watered and vernzalied plants (Fig. 3a; Additional file 6). Under SD, the progression of reproductive meristem development in both genotypes was slower when compared with LD conditions irrespective of vernalization and/or water regime treatments with significant differences observed between the tested genotypes after eight weeks of incubation (Fig. 3b; Additional file 6). After eight weeks of SD incubation, stressed Rum plants subjected to vernalization showed a clear and significantly different advanced developmental stage, while under the same conditions, stressed Steptoe plants showed a clear slower reproductive meristem development (Fig. 3b; Additional file 6). For nonvernalized plants, Rum showed a clear advanced developmental stage after eight weeks of SD conditions, irrespective of water regime treatment, when compared with Steptoe.

At the end of the experiment, the mean values of HD of Rum plants grown under LD conditions and irrespective of vernalization and water regime treatments were significantly lower than the mean values of Steptoe (Additional file 7). On the other hand, vernalized Rum plants showed a significant earlier HD under I $D$ conditions when comnared with non-vernalized Rum plants. Under LD conditions and Loading [MathJax]/jax/output/CommonHTML/fonts/TeX/fontdata.js

Page $11 / 24$ 
irrespective of vernalization treatment, a significant delay in heading was observed in stressed Steptoe plants when compared with well-watered plants (Additional file 7). Under SD conditions, stress-treated and vernalized Rum plants were significantly the earliest to flower when compared with well-watered and vernalized Rum plants (Additional file 7).

The effects of water stress on RWC, stomatal resistance maximum quantum efficiency $(F v / F m)$ of photosystem II have been analyzed in treated plants as an index for drought tolerance of the two tested genotypes. Significant differences between well-watered and stressed plants were observed for the tested parameters in the two tested genotypes under different photoperiod and vernalization conditions (Additional file 8). For instance, the mean values of RWC of the tested genotypes were lower in stressed plants irrespective of photoperiod or vernalization treatments and the effects were more pronounced after four weeks of incubation (Additional file 6). Starting the 4th week, the mean values of RWC of nonvernalized Steptoe plants grown under SD and water deficit conditions were significantly the lowest. Clear effects of water deficit stress on stomatal resistance and maximum quantum efficiency $(\mathrm{Fv} / \mathrm{Fm})$ of photosystem II were also observed in both genotypes irrespective of day length conditions or vernalization treatments (Additional file 8).

The expression patterns of $\mathrm{Vrn}-\mathrm{H} 1, \mathrm{Ppd}-\mathrm{H} 1$ and $H V A 22$ genes were investigated in both tested genotypes in response to water deficit, vernalization and photoperiod treatments at selected time points. After two weeks of LD conditions, the relative expression levels of $\mathrm{Vrn}-\mathrm{H} 1$ were higher in vernalized plants when compared with non-vernalized for both tested genotypes (Fig. 4). Irrespective of vernalization treatment, Rum always showed higher $\mathrm{V} r n-H 1$ expression after two weeks of LD incubation than that observed in Steptoe. Irrespective of water regime treatment, $\mathrm{V} r n-H 1$ expression levels after two weeks of LD incubation were significantly low in non-vernalized Steptoe plants compared with vernalized plants (Fig. 4). After four weeks of LD incubation, the same trend of high expression of $\mathrm{Vrn}-\mathrm{H} 1$ was observed in vernalized plants when compared with non-vernalized plants, however, the expression levels were significantly lower in stressed Steptoe plants when compared with stressed Rum plants (Fig. 4). Under SD conditions, Rum showed higher Vrn-H1 expression levels when compared with Steptoe (Fig. 4).

Interestingly, the expression of $\mathrm{Vrn}-\mathrm{H} 1$ was significantly the highest in stressed and vernalized Rum plants when compared with Rum plants subjected to other combinations.

After two weeks of LD incubation and irrespective of water regime treatment, the $P p d-H 1$ expression in vernalized Rum plants showed the highest levels when compared with non-vernalized Rum (Fig. 4). At the same time, no significant differences were detected between Ppd-H1 levels in Steptoe plants subjected to different combinations of water regime and vernalization. After four weeks of LD incubation and irrespective of water regime treatment, vernalized Rum plants showed lower $P p d-H 1$ expression levels when compared with non-vernalized Steptoe and non-vernalized Rum plants (Fig. 4). For SD conditions, Ppd-H1 levels were slightly higher in Rum plants when compared with Steptoe with a slight increase under well-watered conditions (Fig. 4). For HVA22 gene expression, no major changes were observed between the different growth conditions under SD and LD for both Rum and Steptoe genotypes where 


\section{Discussion}

The occurrence of abiotic stresses in marginal Mediterranean environments, primarily heat and drought, are strongly variable over space and time [35]. In these environments, terminal drought under rainfed conditions can lead to premature termination of plant growth before grain maturity and consequently can affect grain yield severely [36]. Therefore, the adoption of stable and drought tolerant cultivars is considered a useful approach to improve yield in such areas [3]. In this study, late sowing accompanied by drought stress resulted in lower GY when compared with early sowing treatment (Fig. 1a). This is expected knowing that late sowing will subject barley plants to different abiotic stresses, such as drought and heat, which are expected to negatively affect the growth and yield [37]. Furthermore, variations in the response of barley genotypes to different environments and treatments were obvious, confirming that GY was greatly affected by genotypic effects where the adapted local cultivars Rum and Acsad176, outperformed the non-adaptive cultivars, Steptoe and Morex (Fig. 2). In this study, Rum was superior and the most stable genotype under all tested environments, which indicated its general adaptability to multiple environments. Rum is the oldest released cultivar in Jordan that was bred for dry environments by CIMMYT/ICARDA and it is still preferred by many farmers in dry areas receiving more than $250 \mathrm{~mm}$ of rainfall. In many studies, Rum outperformed several Jordanian landraces and cultivars and was considered the most stable genotype under mild drought conditions [37, 38]. Nevertheless, Rum performance was relatively moderate when compared with 150 Jordanian landraces under severe drought conditions and therefore, it is more suited to areas with mild drought conditions 346]. Compared to Rum, Steptoe was the poorest performer and the least stable genotypes across all tested environments and in particular under rainfed conditions (Fig. 2). Similar results were reported recently where Rum outperformed Steptoe in field trials under drought conditions [16] and it was the most drought-affected genotype under controlled conditions [22]. In this study, the GY of tested genotypes was affected by the environment and treatment combinations, which in turn reflect different durations and intensities of drought stress and developmental stage at which the stress occurred. For instance, February-rainfed treatments resulted in a severe reduction in GY when compared with December-rainfed treatments, which could be attributed to severe terminal drought conditions accompanied by early flowering phenotypes associated with the onset of LD conditions. Similar results were found by [37], who found that terminal drought conditions for late sown plants had adverse effects on barley yield.

In this study, drought seemingly accelerated HD by three days under field conditions when compared with irrigated conditions. This is in general agreement with [39], who observed accelerated heading in barley plants under stress conditions. Steptoe was the last genotype to flower across different environments and was the most affected genotype by drought stress. Steptoe was described previously as a late flowering genotype that has a reduced peduncle and few tillers per plant [22]. Such late-flowering behavior was correlated with a severe reduction in GY when compared with early flowering behavior observed in Rum (Additional file 5). This behavior was reported previously under controlled greenhouse conditions, where HD was negatively correlated with GY irrespective of water stress treatment [22]. In the same study, Rum flowered earlier and outperformed Steptoe for GY and other yield-related traits under

Loading [MathJax]/jax/output/CommonHTML/fonts/TeX/fontdata.js ered earlier under field conditions when

Page $13 / 24$ 
compared to Steptoe with a strong positive correlation between early flowering and GY under drought conditions [16]. This is supported further by the fact that in dry environments, delay in flowering time is commonly correlated with yield reductions [40].

Flowering time in temperate cereals, including barley, is a tightly regulated process where flower initiation and development are controlled by environmental signals, primarily by the exposure to low temperatures and day-length $([14,25,41]$. The responses to photoperiod and vernalization classify barley varieties according to their adaptation pattern into winter, spring and facultative types [9]. Such responses are governed by genetic networks and allelic variations in key regulatory genes that fine-tune barley flowering in response to environmental stimuli [10, 42]. During the fall, when barley seeds start to germinate, $\mathrm{Vrn}-\mathrm{H} 3$ is repressed by $\mathrm{Vrn}-\mathrm{H} 2[9,43]$. During winter, vernalization up-regulates $\mathrm{Vrn}-\mathrm{H} 1$, which results in the repression of $\mathrm{Vrn}-\mathrm{H} 2$ in the leaves and, consequently, the activation of $\mathrm{Vrn}-\mathrm{H} 3$ transcription in the spring $[43,44,45]$. Vrn-H2 functional allele was detected in Rum, while it was absent in Steptoe [22]. The presence of $\mathrm{Vrn}-\mathrm{H} 2$ is required to prevent premature flowering under LD conditions particularly after fall sowing [46]. However, no clear repression effect of $\mathrm{V} r n-H 2$ on flowering under LD in Rum was observed, although vernalization treatment seems to accelerate floral meristem development in Rum (Fig. 3 and Additional file 6). Low expression levels of $V r n 1$ were associated with a delay in reproductive meristem initiation in wheat plant [47], while the high expression of $\mathrm{Vrn}-\mathrm{H} 1$ accelerated flowering in barley [12]. Rum carries a spring allele of $\mathrm{V} r n-H 1$, which was up-regulated in response to vernalization and LD conditions in this study (Fig. 4), and this might alleviate the repressive effect of $\mathrm{Vrn}-\mathrm{H} 2$ under LD conditions [31, 43]. On the other hand, $P p d-H 1$ expression was also increased earlier in Rum under LD conditions in response to vernalization, which might indicate that the repression effect of $\mathrm{Vrn}-\mathrm{H} 2$ can be alleviated in vernalized spring barley type as observed previously for vernalized winter types [43]. Interestingly, Steptoe lacks functional $\mathrm{Vrn}-\mathrm{H} 2$ alleles and like Rum carries spring allele of $\mathrm{Vrn}-\mathrm{H} 1$ and a functional $P p d-H 1$ but still, Steptoe behaved differently from Rum under LD conditions, which might indicate that the genetic network governing heading under LD conditions is different from that existing in Rum.

In this study, Rum was more responsive to vernalization treatments and flowered earlier when compared with Steptoe (Additional file 7). In general, the overall gene expression levels of $\mathrm{Vrn}-\mathrm{H} 1 \mathrm{in}$ response to vernalization treatment were higher in Rum than that in Steptoe (Fig. 4). This could explain the faster transition to the reproductive stage that occurred in Rum compared to Steptoe under LD and SD conditions and particularly in response to drought stress under SD conditions. Such differences in $\mathrm{Vrn}-\mathrm{H} 1$ gene expression between genotypes were reported previously where higher expression levels were detected in S42-IL107 compared with Scarlett under LD conditions irrespective of drought treatment [21]. In this study, both tested genotypes carried different $\mathrm{V} r n-H 1$ alleles where Rum has an insertion ( $\mathrm{Vrn}-\mathrm{H1}-\mathrm{T})$ and Steptoe has a deletion ( $\mathrm{Vrn}-\mathrm{H1}-4)$ at $\mathrm{Vrn}-\mathrm{H} 1$ first intron [22], which might explain the differential gene expression in response to different treatments. The high $\mathrm{V} r n-H 1$ expression levels in vernalized Rum plants under SD and drought stress conditions were associated with a clear advanced developmental stage, while Steptoe, under the same conditions, showed a clear slower reproductive meristem development (Fig. 3b; Additional file 6; Fig. 4). This also indicates that even though both genotypes are 
vernalization independent, there are still responses to vernalization in combination with other growth conditions and in response to stress, which might have implications for field-grown plants [19].

In barley, allelic differences in $P p d-H 1$ and $P p d-H 2$ genes are known to be associated with natural variations in the responses to day length [48]. A functional LD-responsive $P p d-H 1$ allele was identified in both Rum and Steptoe, which explain their accelerated flowering responses under LDs conditions when compared with SD conditions [42]. A positive role of the LD-responsive Ppd-H1 allele on GY was observed recently that was associated with shorter growing seasons under drought conditions [16]. Under these conditions, the functional Ppd-H1 allele was associated with increased GFP and increased TKW in barley plants. Still, Rum was found to be hyper-responsive to LD conditions compared to Steptoe indicating the existence of different genetic networks to perceive photoperiod signals in barley plant $[49,50]$. This is further supported by $P p d-H 1$ expression data under LD condition, where both genotypes behaved differently in response to vernalization treatment (Fig. 4). In Rum genotype, the expression level of Ppd$\mathrm{H} 1$ after two weeks of LD incubation was higher under vernalization when compared with non-vernalized conditions, while the opposite was observed after four weeks of LD incubation. Notably, this affected the flowering behavior under LD conditions where vernalized Rum plants flowered earlier than non-vernalized plants (Additional file 7). Furthermore, no clear effect of drought on meristem development in vernalized Rum was observed under LD conditions. A similar trend was reported by [51] where the developmental stage of the apical meristem was similar in introgression lines carrying $P p d-H 1$ under control and stress conditions. In a recent study, [21] found that the expression of $P p d-H 1$ was not affected in response to drought under LD conditions in two tested genotypes. Still, the same study concluded that Ppd-H1 integrates photoperiod and drought stress signals to fine-tune reproductive development in barley. In Steptoe, there was no major difference in $P p d-H 1$ expression under LD conditions after two weeks of incubation, but after four weeks, the expression levels under vernalized conditions were higher when compared with non-vernalized plants. In this study, no clear association was found between $P p d-H 1$ and $\mathrm{Vrn}-\mathrm{H} 1$ expression patterns under LD conditions with the flowering behavior in Steptoe under drought conditions (Fig. 4).

$P p d-H 2$ is another gene that has been long acknowledged as responsible for the acceleration of flowering in facultative barley types in response to the SD photoperiod and under mild winter conditions [52]. Ppd$H 2$ was identified previously in Rum and not in Steptoe [22], which might explain the failure of Steptoe to flower under SDs conditions. It was proposed that $P p d-H 2$ promotes the early flowering of winter cultivars irrespective of photoperiod conditions and the existence of a dominant allele can promote flowering in plants that have not satisfied their vernalization requirement [52]. Barley genotypes carrying the dominant allele of $P p d-H 2$ showed higher expression levels of $\mathrm{Vrn}-\mathrm{H} 1$ and this might explain the higher levels of $\mathrm{Vrn}-\mathrm{H} 1$ in Rum plants under SD conditions. It is worth noting that the expression level of $\mathrm{Vrn}-\mathrm{H} 1 \mathrm{under}$ SD and stress conditions was higher in vernalized Rum plants (Fig. 4). An interplay between Ppd-H1 and Ppd$\mathrm{H} 2$ to fine-tune plant development under SD and LD conditions in response to vernalization and stress conditions was recently suggested [16]. 


\section{Conclusions}

In this study, the field performance of four selected spring barley genotypes was assessed across different environments and treatments. Rum and Acsad176 were well-adapted and stable across different environments and management practices when compared with Morex and Steptoe. The delayed heading in Steptoe was correlated negatively with GY under drought conditions, while it was associated with better performance in Rum. Analyzing the responses of both genotypes under controlled conditions identified a link between shoot apical meristem development under SD and drought stress conditions in vernalized Rum plants that were associated with higher gene expression of the $\mathrm{Vrn}-\mathrm{H} 1 \mathrm{gene}$. Furthermore, accelerated flowering in Rum plants was observed in response to vernalization under LD conditions. This was also reflected in the early expression of $\mathrm{Vrn}-\mathrm{H} 1$ and $\mathrm{Ppd}-\mathrm{H} 1$ in Rum plants under these conditions. Under rainfed conditions, the early sowing of Rum subjected the plants to SD and vernalization followed by the onset of LD conditions at the end of the season. Under such conditions, a 30\% reduction in GY was observed in Rum compared with a $60 \%$ reduction in Steptoe. This highlights the importance of selecting genotypes that can integrate vernalization and photoperiod responses to secure stable yield production in dry environments. Further studies are needed to dissect the genetic basis of floral meristem development and to identify QTL associated with yield stability under drought conditions. Finally, matching the developmental behavior of barley genotypes using different management procedures and dissecting the genetic information of these behaviors will help in developing new genotypes with stable performance under dry conditions.

\section{Declarations}

\section{Funding}

This research was funded partially by the Deanship of Scientific Research, The University of Jordan (Amman, Jordan) and the Arab Fund for Economic and Social Development (AFESD; Kuwait) project through ICARDA.

\section{Conflict of Interest Statement}

The authors have declared that no conflict of interest exists.

\section{Acknowledgments}

We sincerely acknowledge Mr. Talal Ebdah (The University of Jordan) and Mr. Mahmmoud Al-Qudah (Rabba Center for Agriculture Research, NARC) for their assistant in the field work. We sincerely acknowledge Dr. Aladdin Hamwieh for his assistant in the statistical analysis. We sincerely acknowledge the financial support of the Arab Fund for Economic and Social Development (AFESD; Kuwait) project to 


\section{Author Contributions}

AMA, JAE and JYA conceived, designed the experiments, analyzed the data and wrote the manuscript. JAE, RAS, ZAA and AAB supervised the field work, collected the phenotypic data and helped in data analysis. RB helped in site analysis, weather data and related measurements and their analysis. ZA helped in controlled experiments, meristem dissecting and their data analysis. RAS and JYA helped in controlled experiments, physiological measurements and their data analysis. SH and TH helped in molecular work, gene expression and data analysis. All authors edited and provided a critical review of the manuscript. All authors read and approved the final manuscript.

\section{Availability of data and materials}

The data sets supporting the results of this article will be freely available upon request to corresponding author: a.alabdallat@ju.edu.jo for non-commercial use only

\section{References}

1. Newman RK, Newman CW. Barley for food and health: Science, technology, and products. John Wiley \& Sons. 2008; p.56-94.

2. Horsley RD, Franckowiak JD, Schwarz PB. Barley. In Cereals. Springer, New York, NY. 2009; p. 227250. https://doi.org/10.1007/978-0-387-72297-9_7

3. Visioni A, Al-Abdallat A, Elenien JA, Verma RP, Gyawali S, Baum M. Genomics and molecular breeding for improving tolerance to abiotic stress in barley (Hordeum vulgare L.). In Genomics Assisted Breeding of Crops for Abiotic Stress Tolerance. Springer, Cham. 2019; $2: 49-68$. https://doi.org/10.1007/978-3-319-99573-1_4

4. Jedmowski C, Ashoub A, Momtaz O, Brüggemann W. Impact of drought, heat, and their combination on chlorophyll fluorescence and yield of wild barley (Hordeum spontaneum). J Bot. 2015; 2015:1-9. http://dx.doi.org/10.1155/2015/120868

5. Araus JL, Slafer GA, Royo C, Serret MD. Breeding for yield potential and stress adaptation in cereals. Crit Rev Plant Sci. 2008; 27(6):377-412. https://doi.org/10.1080/07352680802467736.

6. Anderson R, Bayer PE, Edwards D. Climate change and the need for agricultural adaptation. Curr Opin Plant Biol. 2020; 56:197-202. https ://doi.org/10.1016/j.pbi.2019.12.006

7. Lu HD, Xue JQ, Guo DW. Efficacy of planting date adjustment as a cultivation strategy to cope with drought stress and increase rainfed maize yield and water-use efficiency. Agric Water Manag. 2017; 179:227-35. https://doi.org/10.1016/j.agwat.2016.09.001

8. Jung C, Pillen K, Staiger D, Coupland G, von Korff M. Recent advances in flowering time control. Front Plant Sci. 2017; 7:2011. https://doi.org/10.3389/fpls.2016.02011

9. Distelfeld A, Li C, Dubcovsky J. Regulation of flowering in temperate cereals. Curr Opin Plant Biol. Loading [MathJax]/jax/output/CommonHTML/fonts/TeX/fontdata.js j8.12.010 
10. Campoli C, von Korff M. Genetic control of reproductive development in temperate cereals. Adv Bot Res. 2014; 72:131-58. https://doi.org/10.1016/B978-0-12-417162-6.00005-5

11. Gol L, Tomé F, von Korff M. Floral transitions in wheat and barley: interactions between photoperiod, abiotic stresses, and nutrient status. J Exp Bot. 2017; 68(7):1399-410. https://doi.org/10.1093/jxb/erx055

12. Sasani S, Hemming MN, Oliver SN, Greenup A, Tavakkol-Afshari R, Mahfoozi S, Poustini K, Sharifi HR, Dennis ES, Peacock WJ, Trevaskis B. The influence of vernalization and daylength on expression of flowering-time genes in the shoot apex and leaves of barley (Hordeum vulgare). J Exp Bot. 2009; 60(7):2169-78. https://doi.org/10.1093/jxb/erp098

13. Saisho D, Ishii M, Hori K, Sato K. Natural variation of barley vernalization requirements: implication of quantitative variation of winter growth habit as an adaptive trait in East Asia. Plant Cell Physiol. 2011; 52(5):775-84. https://doi.org/10.1093/pcp/pcr046

14. Trevaskis B, Tadege M, Hemming MN, Peacock WJ, Dennis ES, Sheldon C. Short vegetative phaselike MADS-box genes inhibit floral meristem identity in barley. Plant Physiol. 2007;143(1):225-35. https://dx.doi.org/10.1104\%2Fpp.106.090860

15. Trevaskis $\mathrm{B}$. The central role of the VERNALIZATION1 gene in the vernalization response of cereals. Funct Plant Biol. 2010; 37(6):479-87.. https://doi.org/10.1071/FP10056

16. Wiegmann M, Maurer A, Pham A, March TJ, Al-Abdallat A, Thomas WT, Bull HJ, Shahid M, Eglinton J, Baum M, Flavell AJ. Barley yield formation under abiotic stress depends on the interplay between flowering time genes and environmental cues. Sci Rep. 2019; 9(1):1-6. https://doi.org/10.1038/s41598-019-42673-1

17. Galiba G, Vágújfalvi A, Li C, Soltész A, Dubcovsky J. Regulatory genes involved in the determination of frost tolerance in temperate cereals. Plant Sci. 2009;176(1):12-9. https://doi.org/10.1016/j.plantsci.2008.09.016

18. Von Korff M, Grando S, Del Greco A, This D, Baum M, Ceccarelli S. Quantitative trait loci associated with adaptation to Mediterranean dryland conditions in barley. Theor Appl Genet. 2008; 117(5):65369. https://doi.org/10.1007/s00122-008-0787-2

19. Casao MC, Igartua E, Karsai I, Bhat PR, Cuadrado N, Gracia MP, Lasa JM, Casas AM. Introgression of an intermediate $V R N H 1$ allele in barley (Hordeum vulgare L.) leads to reduced vernalization requirement without affecting freezing tolerance. Mol Breed. 2011; 28(4):475-84. https://doi.org/10.1007/s11032-010-9497-y

20. Habte E, Müller LM, Shtaya M, Davis SJ, von Korff M. Osmotic stress at the barley root affects expression of circadian clock genes in the shoot. Plant Cell Environ. 2014;37(6):1321-37. https://doi.org/10.1111/pce.12242

21. Gol L, Haraldsson EB, von Korff M. Ppd-H1 integrates drought stress signals to control spike development and flowering time in barley. J Exp Bot. 2021; 72(1):122-36. https://doi.org/10.1093/jxb/eraa261 
22. Al-Ajlouni ZI, Al-Abdallat AM, Al-Ghzawi AL, Ayad JY, Abu Elenein JM, Al-Quraan NA, Baenziger PS. Impact of pre-anthesis water deficit on yield and yield components in barley (Hordeum vulgare L.) plants grown under controlled conditions. Agronomy. 2016; 6(2):33.

https://doi:10.3390/agronomy6020033

23. Olivoto T, Lúcio AD. metan: An R package for multi-environment trial analysis. Methods Ecol Evol. 2020; 11(6):783-9. https://doi.org/10.1111/2041-210X.13384

24. Yan W. GGEbiplot-A Windows application for graphical analysis of multienvironment trial data and other types of two-way data. Agron J. 2001; 93(5):1111-8.

https://doi.org/10.2134/agronj2001.9351111x

25. Hemming MN, Peacock WJ, Dennis ES, Trevaskis B. Low-temperature and daylength cues are integrated to regulate FLOWERING LOCUS T in barley. Plant Physiol. 2008; 147(1):355-66. https://doi.org/10.1104/pp.108.116418

26. Doorenbos J. Guidelines for predicting crop water requirements. Food and Agriculture organization. Rome, Irrig. Drainage pap. 1975; 24.

27. Al Abdallat AM, Ayad JY, Elenein JA, Al Ajlouni Z, Harwood WA. Overexpression of the transcription factor HvSNAC1 improves drought tolerance in barley (Hordeum vulgare L.). Mol Breeding. 2014; 33(2):401-14. https://doi.org/10.1007/s11032-013-9958-1

28. Barrs HD, Weatherley PE. A re-examination of the relative turgidity technique for estimating water deficits in leaves. Aust J Biol Sci. 1962; 15(3):413-28. https://doi.org/10.1071/BI9620413.

29. Waddington SR, Cartwright PM, Wall PC. A quantitative scale of spike initial and pistil development in barley and wheat. Ann Bot. 1983; 51(1):119-30.

https://doi.org/10.1093/oxfordjournals.aob.a086434

30. Zadoks JC, Chang TT, Konzak CF. A decimal code for the growth stages of cereals. Weed Res. 1974; 14(6):415-21. https://doi.org/10.1111/j.1365-3180.1974.tb01084.x

31. Trevaskis B, Hemming MN, Peacock WJ, Dennis ES. HvVRN2 responds to daylength, whereas HvVRN1 is regulated by vernalization and developmental status. Plant Physiol. 2006; 140(4):1397405. https://doi.org/10.1104/pp.105.073486

32. Hemming MN, Walford SA, Fieg S, Dennis ES, Trevaskis B. Identification of high-temperatureresponsive genes in cereals. Plant Physiol. 2012; 158(3):1439-50.

https://doi.org/10.1104/pp.111.192013

33. Shen Q, Chen CN, Brands A, Pan SM, Tuan-Hua DH. The stress-and abscisic acid-induced barley gene HVA22: developmental regulation and homologues in diverse organisms. Plant Mol Biol. 2001; 45(3):327-40. https://doi.org/10.1023/A:1006460231978

34. Vandesompele J, De Preter K, Pattyn F, Poppe B, Van Roy N, De Paepe A, Speleman F. Accurate normalization of real-time quantitative RT-PCR data by geometric averaging of multiple internal control genes. Genome Biol. 2002; 3(7):1-2. https://doi.org/10.1186/gb-2002-3-7-research0034

35. Baum M, Von Korff M, Guo P, Lakew B, Hamwieh A, Lababidi S, Udupa SM, Sayed H, Choumane W, Loading [MathJax]/jax/output/CommonHTML/fonts/TeX/fontdata.js eeding strategies for drought tolerance in barley. 
In Genomics-assisted crop improvement. Springer, Dordrecht; 2007. p. 51-79. https://doi.org/10.1007/978-1-4020-6297-1_3

36. Al-Abdallat AM, Karadsheh A, Hadadd NI, Akash MW, Ceccarelli S, Baum M, Hasan M, Jighly A, Elenein JA. Assessment of genetic diversity and yield performance in Jordanian barley (Hordeum vulgare L.) landraces grown under Rainfed conditions. BMC Plant Biol. 2017; 17(1):1-3. https://doi.org/10.1186/s12870-017-1140-1

37. Samarah NH, Alqudah AM, Amayreh JA, McAndrews GM. The effect of late-terminal drought stress on yield components of four barley cultivars. J Agron Crop Sci. 2009; 195(6):427-41. https://doi.org/10.1111/j.1439-037X.2009.00387.x

38. Al-Sayaydeh R, Al-Bawalize A, Al-Ajlouni Z, Akash MW, Abu-Elenein J, Al-Abdallat AM. Agronomic evaluation and yield performance of selected barley (Hordeum vulgare L.) landraces from Jordan. Int J Agron. 2019; 2019:1-12. https://doi.org/10.1155/2019/9575081

39. Tavakol E, Elbadry N, Tondelli A, Cattivelli L, Rossini L. Genetic dissection of heading date and yield under Mediterranean dry climate in barley (Hordeum vulgare L.). Euphytica. 2016; 212(2):343-53. https://doi.org/10.1007/s10681-016-1785-0

40. Rollins JA, Habte E, Templer SE, Colby T, Schmidt J, Von Korff M. Leaf proteome alterations in the context of physiological and morphological responses to drought and heat stress in barley (Hordeum vulgare L.). J Exp Bot. 2013; 64(11):3201-12. https://doi.org/10.1093/jxb/ert158

41. Maurer A, Draba V, Jiang Y, Schnaithmann F, Sharma R, Schumann E, Kilian B, Reif JC, Pillen K. Modelling the genetic architecture of flowering time control in barley through nested association mapping. BMC Genomics. 2015; 16(1):1-2. https://doi.org/10.1186/s12864-015-1459-7

42. Campoli C, Shtaya M, Davis SJ, von Korff M. Expression conservation within the circadian clock of a monocot: natural variation at barley $P p d-H 1$ affects circadian expression of flowering time genes, but not clock orthologs. BMC Plant Biol. 2012; 12(1):97. https://doi.org/10.1186/1471-2229-12-97

43. Mulki MA, von Korff M. CONSTANS controls floral repression by up-regulating VERNALIZATION2 (VRN-H2) in barley. Plant Physiol. 2016; 170(1):325-37. https://doi.org/10.1104/pp.15.01350

44. Fu D, Szűcs P, Yan L, Helguera M, Skinner JS, Von Zitzewitz J, Hayes PM, Dubcovsky J. Large deletions within the first intron in VRN-1 are associated with spring growth habit in barley and wheat. MolGenet Genom. 2005; 273(1):54-65. https://doi.org/10.1007/s00438-004-1095-4

45. Chen A, Dubcovsky J. Wheat TILLING mutants show that the vernalization gene VRN1 downregulates the flowering repressor VRN2 in leaves but is not essential for flowering. PLoS Genet. 2012; 8(12):e1003134. https://doi.org/10.1371/journal.pgen.1003134

46. Cockram J, Jones H, Leigh FJ, O'Sullivan D, Powell W, Laurie DA, Greenland AJ. Control of flowering time in temperate cereals: genes, domestication, and sustainable productivity. J Exp Bot. 2007; 58(6):1231-44. https://doi.org/10.1093/jxb/erm042

47. Pearce S, Vanzetti LS, Dubcovsky J. Exogenous gibberellins induce wheat spike development under short days only in the presence of VERNALIZATION1. Plant Physiol. 2013; 63(3):1433-45. 
48. Turner A, Beales J, Faure S, Dunford RP, Laurie DA. The pseudo-response regulator Ppd-H1 provides adaptation to photoperiod in barley. Science. 2005; 310(5750):1031-4. DOI: 10.1126/science.1117619.

49. Faure S, Higgins J, Turner A, Laurie DA. The FLOWERING LOCUS T-like gene family in barley (Hordeum vulgare). Genetics. 2007; 176(1):599-609. https://doi.org/10.1534/genetics.106.069500

50. Karsai I, Szűcs P, Kőszegi B, Hayes PM, Casas A, Bedő Z, Veisz O. Effects of photo and thermo cycles on flowering time in barley: a genetical phenomics approach. J Exp Bot. 2008; 59(10):2707-15. https://doi.org/10.1093/jxb/ern131

51. Haile EH. The effect of natural variation at Ppd-H1 and HvELF3 on responses to osmotic stress in barley (Hordeum vulgare) (Doctoral dissertation, Universität zu Köln); 2013.

52. Casao MC, Karsai I, Igartua E, Gracia MP, Veisz O, Casas AM. Adaptation of barley to mild winters: a role for PPDH2. BMC Plant Biol. 2011; 11(1):1-3. https://doi.org/10.1186/1471-2229-11-164

\section{Figures}
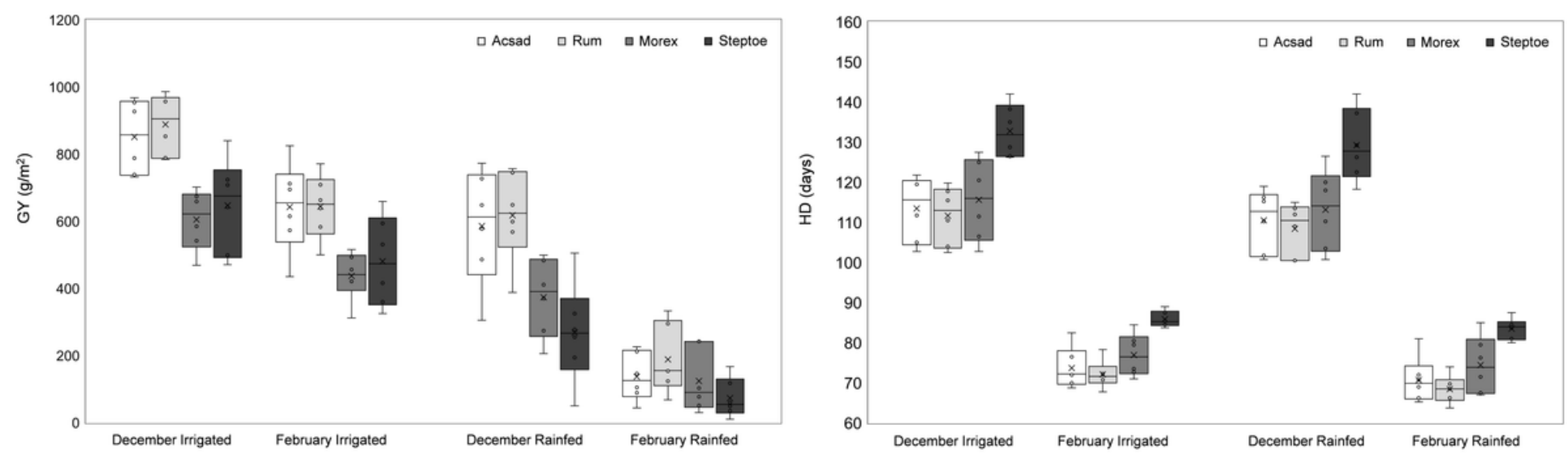

\section{Figure 1}

Box-Whisker plots showing genotypic variations for GY (a) and HD (b) traits per sowing date and water regime treatments combinations. 

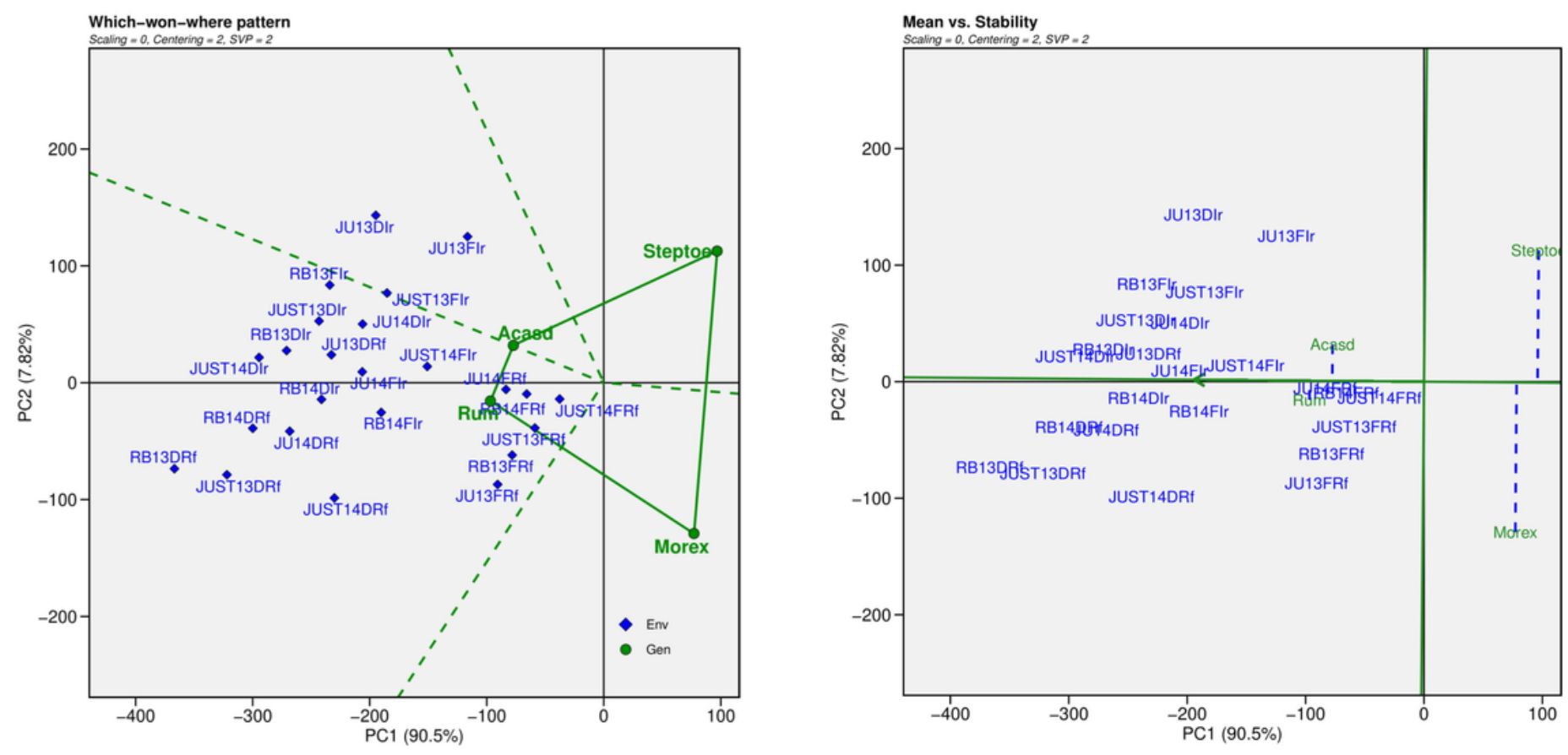

Figure 2

GGE biplot analysis of GY for four barley genotypes across 24 environments (season: 2012 (12) and 2013 (13); location: JU, JUST and RB; sowing dates: December (D) and February (F); water regimes: Irrigated (Ir) and Rainfed (Rf)). (A) Which won and where pattern for the tested genotypes across 24 environments. (B) Stability analysis for the tested genotypes across 24 environments.
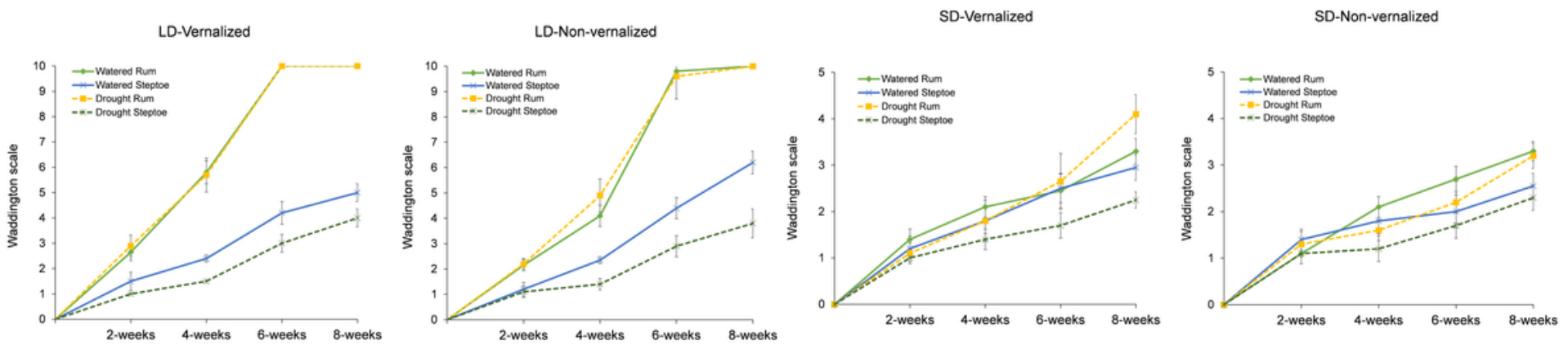

\section{Figure 3}

Shoot apex development in two barley genotypes (Rum and Steptoe) in response to to different comhinatinn e of vernalization nhotnnerind and water-deficit treatments after 2, 4, 6 and 8 weeks post Loading [MathJax]/jax/output/CommonHTML/fonts/TeX/fontdata.js 
emergence. (A) Shoot apex development under LD conditions. (B) Shoot apex development under SD conditions. At each time-point, four plants were dissected and the shoot apex developmental stage was scored according to the Waddington scale [62]. Values are mean \pm SD of four replicates.
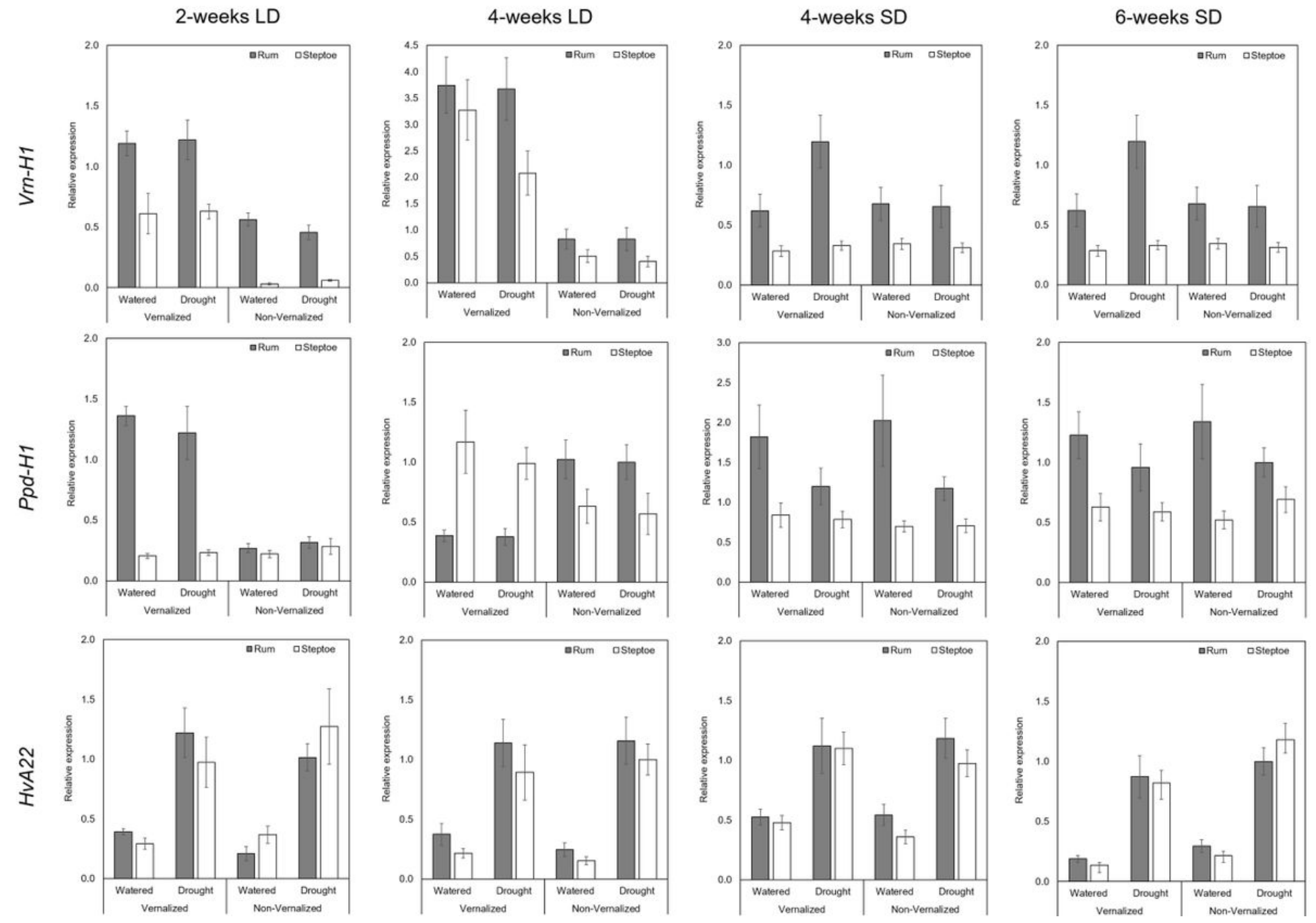

\section{Figure 4}

Gene expression analysis of Vrn-H1, Ppd-H1 and HVA22 in two barley genotypes (Rum and Steptoe) subjected to different combinations of vernalization, photoperiod and water-deficit treatments. For LD, samples were collected after two and four weeks post emergence. For SD, samples were collected after four and six weeks post emergence weeks Values are mean \pm SD of three technical replicates.

\section{Supplementary Files}

This is a list of supplementary files associated with this preprint. Click to download.

- Additionalfile1.xlsx

- Additionalfile2.xIsx 
- Additionalfile4.jpg

- Additionalfile5.pptx

- Additionalfile6.pptx

- Additionalfile7.jpg

- Additionalfile8.pptx 